\title{
Automotive Software and Service Engineering (ASSE) - an exploration of challenges and trends in an industry experts' view
}

\author{
Andreas Zauner', Holger Hoffmann'1, Jan Marco Leimeister², Helmut Krcmar' \\ ${ }^{1}$ Lehrstubl für Wirtschaftsinformatik, Technische Universität München \\ ${ }^{2}$ Fachgebiet Wirtschaftsinformatik, Universität Kassel
}

\section{Introduction and Motivation}

Mobile and software based value-added applications in an automobile, known as Automotive Software and Services (Reichwald et al. 2007), represent a differentiation factor and are currently increasing in importance in a "young generation" (Stolte 2008) of customers. And hence, Automotive Software and Services are used as means for differentiation and also to increase customers loyalty (Mercer 2004; Reichwald et al. 2007). The amount of software in an automobile - which was only 60MB in 2003 (Saad 2003) - is said to increase to more than 1 Gigabyte in 2010 (Pretschner et al. 2007). This development forces car manufacturers to change the way they think about their offers. Instead of only being producers of cars, who loose customer contact after selling the car, they are moving more and more towards providers of holistic solutions which supply the customer with new and different services throughout the automobile's entire lifetime (Mercer 2004).

Wireless broadband technologies such as UMTS, WiMAX and widely available wireless networks, enable new mobile applications and generate new expectations concerning mobile applications. In addition to mobile devices like mobile phones, the automobile itself more and more becomes a mobile application, too. Western European people are mobilized 80 minutes every single day in average. The majority of this time, they are sitting in their cars (Statistisches Bundesamt 2006). Permanently installed navigation systems using GPS enabling location-independent services based on localization are state of the art in many vehicles and they are often extended with infotainmant applications (Ehmer 2002). Furthermore, applications of traffic telematics (Nora and Minc 1978) can be used, like the emergencyCall (eCall) in case of accidents and also applications which exchange data between different cars or the surrounding infrastructure using wireless networks (Car-2-Car or Car-2-Infrastructure communication). In the future, there should be vehicles which support a 24/7 and location-independent connection to the world wide web 
in terms of a „Connected Life“ (Stolte 2008). These will enable all kinds of webbased services, from a theater reservation to the provision of current (sporting) news. Automotive Software and Services are the most interesting factors of innovation concerning all stakeholders in the automotive industry: „80\% of all future innovations will consist of software." (Mercer 2004). This research focuses only on mobile services which are generating additional value for the user. Integrated automotive software and services, like control units, are excluded.

On the following pages, there is an introduction to basic concepts and relationships and an overview of trends and future developments in the field of Automotive Software and Services. For this purpose, the responds to the empirical study, the data collection process and finally the condensed results will be described. Based on these results, a framework architecture with architectural components is developed that will serve as a recommended course of action for science and industry. While we understand the diversity of software and software based systems found in today's automobiles, this paper will be focused on Automotive Software and Services which are categorized as being a part of the tertiary sector of tasks in an automobile (Bubb 2003; Ehmer 2002) and on those which reach the secondary sector describing advanced driver assistance systems. Again, topics concerning embedded software, for example automotive control units, are excluded explicitly.

\section{Basics and Structure of the Expert Survey}

The aim of the survey is to identify the current state of Automotive Software and Services in science and industry to determine challenges and obstacles and to discover trends and strategies for the future. The expert survey method was chosen deliberately because no opinion should be influenced by a discussion between the experts, as it would be using a Delphi method, for example. In the following sections, we present the fundamentals of our expert survey. The design and implementation of the expert survey is based on the model of the phases of data collection by Nieschlag (Nieschlag et al. 2002), a respected model in German social sciences. In this study, the model was adapted and applied in such a manner that it can respond to the research question and the research obstacles very well. Figure 1 represents this model.

\subsection{Methodological Basics of the Expert Survey}

The expert survey is a method of empirical social research used to gain knowledge about a particular subject area by a "key informant" (Rubin and Rubin 2005). Here, it is expected that the "key informant" also has information about the knowledge and efforts of other players in his scope of tasks which offer him the possibility to evaluate and to classify them. The interview will be conducted as a semi- 

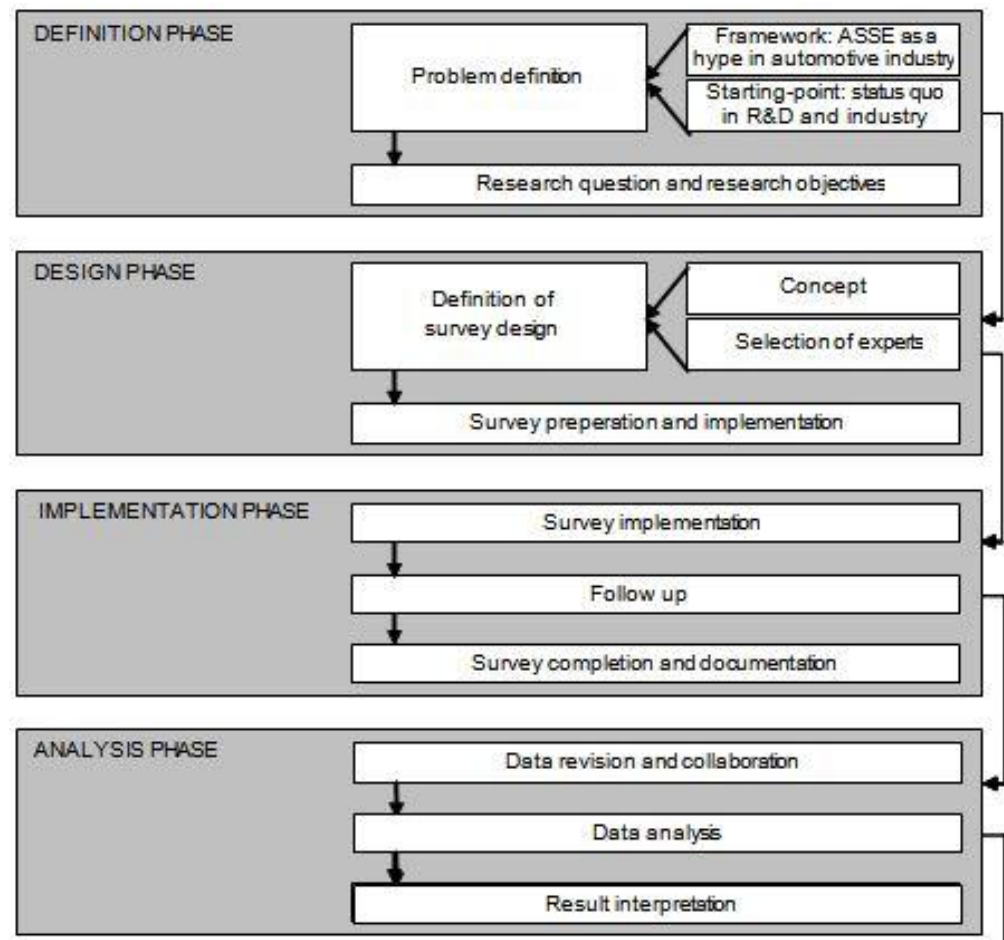

COMMUNICATIONPHASE

Result presentatior

Figure 1: Survey design and process (adopted from (Leimeister et al. 2007; Nieschlag et al. 2002))

structured interview (Gläser and Laudel 2004). In this type of interview, only a few questions are prepared in advance and the majority of the questions are developed and formulated during the interview itself, in response to the answers of the interviewee. This allows a very high flexibility, since neither question wording nor the order of the questions are binding (Gläser and Laudel 2004). In addition, the experts are confronted with statements by other experts and therefore they are forced to respond further in the context of their company. The aim of the interview guide is to identify the thoughts and actions of the various experts and to get an idea about their strategies and their aspirations for the future.

\subsection{Structure and Purpose of the Interview Guide}

An initial and very important knowledge base for Automotive Software and Service Engineering was generated through an extensive literature, internet and data- 
base review. Subsequently, different groups were identified and compared based on publications (papers, press releases etc.) and publicly available information (reviews of other experts, reviews of companies), and initial differences in their policies and practices were recognized. These findings have been compared with scientific literature (Bubb 2003; Mercer 2004; Reichwald et al. 2007; Reichwald et al. 2002), so that an interview guide could be created, which validates theory generated theses of the survey. Knowingly, the survey uses very general questions in order to obtain statements about the importance of partly already existing approaches in practice. The survey should serve to evaluate results documented in literature. In addition to the introductory questions about the position and areas of responsibility of the interviewee, as well as a brief explanation of the topic, the main part of the interview is divided into three thematic blocks.

The first block deals with questions about definition and categorization of automotive software and services in their respective employers. In the second thematic block, the aim is to obtain information about competition and competitors of the respondents by focusing firstly on their strengths and weaknesses in the development of automotive services and secondly there should be an estimate of the competitors' approaches. Finally, the third thematic block deals with the future of automotive software and services. Therefore, the experts were asked to describe the relevant / important / essential opportunities (mobile) applications can offer concerning value-added services and future customer needs can generate in three, five or ten years in future. After the final question of whether something important had been forgotten, the interview was completed with words of thanks.

\subsection{Feedback, Implementation and Evaluation of the Survey}

The goal of the expert survey is to obtain a comprehensive picture of Automotive Software and Services. Therefore, various contacts must be questioned. These contacts are distinguished in their individual roles in industry: OEMs, suppliers, 3 rd party organizations (such as telecommunications providers) and associations or interest groups (such as ADAC, VDI, VDA). Furthermore, a group of consultants is integrated into the survey which has a superior perspective. Based on the categorization of different stakeholders, appropriate contacts were selected. The aim of the survey is the coverage of the German market, in the first stage. In this manner, 60 contacts were identified and personal email invitations were sent. 20 experts committed to the survey, making up a very high participation rate of $33 \%$. Normally, the response rate for such an approach is not higher than 13\% (Harkness et al. 1998; Porst 1999). Sending a survey including a friendly letter without further action doesn't usually achieve return rates higher than 20\% (Dieckmann 1995). The increase of the quota, according to the source of $50 \%$ to $150 \%$, is a clear indication of the relevance of Automotive Software and Services in industry.

The interviews were conducted by telephone in July 2008. The interviewees were asked to answer the questions openly and to express their personal opinions. 
The data analysis procedure is based on the structuring of the equally weighted expert opinions, i.e. the demarcation of their distinct perspectives and grouping of common and invariant components into topics. Keywords (items) have been identified and grouped using code books (Nieschlag et al. 2002) to obtain significant viewpoints. Then, the so-described keyword-cluster was explained in more detail. To ensure an objective selection and grouping of items (Intercoder reliability), this step was carried out independently by two persons, whose final results have been consolidated (Rubin and Rubin 2005). Intercoder reliability can be calculated using a statistical measure. The Cohen's Kappa has the value of 0.81 (Lombard et al. 2002). Such a high value is, according to (Bakeman 2000) completely satisfactory, according to Greve / Wentura (Greve and Wentura 1997) excellent, and declared by Landis / Koch (Landis and Koch 1977) as an almost perfect agreement. This high intercoder reliability guarantees that the results of this survey represent an objective and general picture of the distinct views.

\section{Results of the Expert Survey}

\subsection{Challenges/Obstacles}

The challenges in Automotive Software and Services to the automotive industry are manifold (Fig. 2).

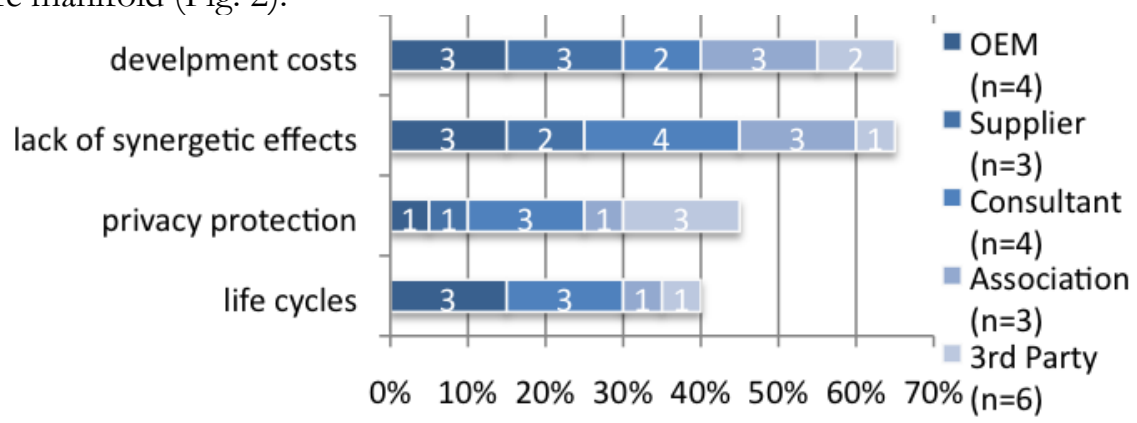

Figure 2: Challenges - frequency of mentions grouped by stakeholder

The customer benefits and the development costs of Automotive Software and Services have to be adjusted. For Automotive Software and Services, very high development costs may apply. A new service costs a company 60-70 million Euros in development expenses (Supplier1 2008). This sum is a large investment for an OEM or Tier 1 supplier and it is not as easy to sell the 2,500-3,500 Euro expensive permanently installed equipment to the customer (Supplier1 2008). In the past, OEMs lost a lot of money. While OEMs have developed new systems, they only looked at those systems which could only be sold in vehicles of the upper middle and upper classes (Supplier3 2008). Again, the distinction must be what customers 
actually want, in order to achieve high sales figures and to cover the development costs. Furthermore, no OEM wants to develop the first new services because these services can only be protected 3 to 5 -years and then the competitors can use the same services while bypassing their own development (OEM1 2008). The development costs can be adjusted by increasing the acceptance of customers (Supplier2 2008) to use these new services. It is necessary to distinguish between value and customer expectation. While an ESP in the car is no added value, a night vision assistant is a system where a surcharge will occur. The customer himself will personally decide whether he wants to buy this system or not (Association3 2008; Frost\&Sullivan 2003; Fuhr 2001; Werder 2005). The companies expect that customers are not willing to spend much money for such services (Consultant2 2008; Supplier1 2008; Supplier2 2008; Supplier3 2008). There is also a discrepancy between what the customer wants and what the manufacturer can provide for a reasonable price (OEM1 2008). The manufacturer is faced with the problem that he has to build what the customer wants. But then, an OEM has to offer services customers actually need but they are not even aware that these services exist (Association3 2008). In a customer's view Automotive Software and Services are offered free of charge (OEM1 2008). If customers accept and recognize the added value of these services, they will be willing to pay for it.

Another challenge is data security and privacy in the "Connected Car" (Stolte 2008; Supplier3 2008). Notably, in the Car-2-Car and Car-2-Infrastructure, the question arises who should share what kind of data with whom (Association2 2008). This new technology should not become an extended arm of the law. (Association 2008). This must be taken strictly to the fact that information about driving, about speed etc. stays within the driver and will only be made available to road users that need it and are entitled to it. While this privacy issue is still a strong reason for discussion in the European region, it is already solved in the Asian market. But this topic actually is a social issue answering the question how to deal with data (Association3 2008). The basically really good idea of C2X could be undermined by simple psychological aspects (Consultant3 2008).

A major problem for OEMs and suppliers are the different product life cycles (Hartmann 2004; Mohan 2006). There are the old-established automobile manufacturers with development cycles of 7 years which are compared to a young industry of service developers with a development cycle of 6 months (Association2 2008; Consultant3 2008). Obviously, the traditional manufacturers can barely keep up with companies such as telecommunication or third party companies belonging into the navigation system sector. There are technological developments which are thought out very well, are functional and are high in quality. But these are overwhelmed (Consultant3 2008) because they simply have too long development times. Car manufacturers are not flexible enough, even wall off from the market and refuse to refit functional solutions into their vehicles (Consultant3 2008; OEM1 2008), although they are better than their own. 
A final obstacle is the lack of synergetic effects through cross-company teams. In the view of many interviewees, OEMs do not have the expertise, efficiency and structure to develop profitable and innovative Automotive Software and Services (Association3 2008; Consultant1 2008). There has also been a paradigm shift in the automotive industry (Supplier2 2008). In the past, all the knowledge about the car was based in the OEMs' companies. If they needed help they shared their knowledge with their Tier 1 suppliers. But there is a different approach in the present. The knowledge about Automotive Software and Services is mostly based at the Tier 1 suppliers, the telecommunications companies and other third parties, such as software companies. But OEMs rely still on their own expertise. Furthermore, many developments are not yet thought through, even from the business model and many OEMs are still in the experimental stage (Consultant1 2008). Many OEMs have not yet understood the meaning of software development. They treat software as if it was a metal part (Consultant1 2008). This issue of software engineering doesn't fit into a general automotive workflow for years (OEM2 2008). The OEMs are still using an old business model which is not successfully adoptable for new services (3rdParty1 2008). There are too many things the OEMs are doing on their own. They only want to skim their market shares and do not see themselves as part of a whole construct (3rdParty1 2008; Consultant1 2008). The perfect solution OEMs are looking for does not exist! (3rdParty1 2008).

\subsection{Development Trends}

In the automotive industry, there are a number of trends concerning Automotive Software and Service Engineering (Fig. 3).

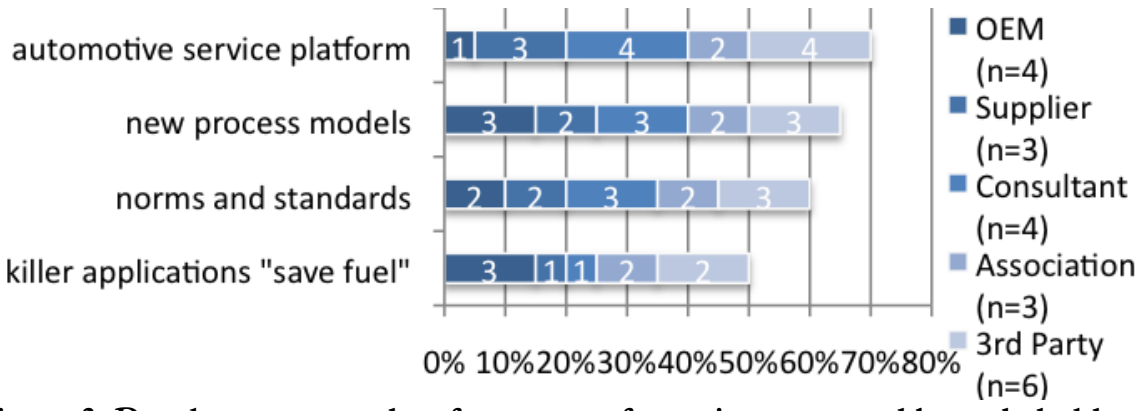

Figure 3: Development trends - frequency of mentions grouped by stakeholders

A general automotive service platform which could be integrated within the car would be a solution for almost all challenges. However, there are three different platforms the experts suggested. Each of them could be the best solution on its own and could work successfully. The mentioned platforms are a telematic-based toll system for passenger cars (Association1 2008; Consultant3 2008; Springer 
2008; Supplier1 2008; Supplier2 2008), a digital broadcasting radio using TPEGformat (3rdParty2 2008; Association2 2008) and finally the eCall using UMTS (3rdParty1 2008; Association2 2008; Springer 2008; Steiger 2008). A telematicbased toll system would imply that a toll collection data unit is integrated in every car, as it is already standard in trucks. Other services can easily be mounted onto this unit and can therefore reach a bigger part of the market (Supplier1 2008).

The technical implementation of this unit would not be a problem, too (Springer 2008). However, this topic has a political aspect, too. In Germany, the issue of a car toll system has to be discussed, priory. Here, the opinions diverge: While suppliers support a car toll system because of its future potential in terms of gaining higher revenues (Supplier1 2008; Supplier2 2008), associations and consumer advocates are worried about the new developments (Association1 2008; Association2 2008). A toll system has completely different political goals and objectives as Car-2-Car communication (Association1 2008). But still, a car toll system could be a good solution if open and standardized interfaces are implemented (3rdParty1 2008; Consultant3 2008). Digital radio broadcasting is a second possibility. However, the units (e.g. radio systems) which are integrated in cars are still using the old TMC-format instead of the new TPEG-format. The TPEG-format offers more functions and can therefore handle more content. Plus, there is already a possibility to communicate with infrastructure (3rdParty2 2008). The only problem is that the technological sophisticated platform does not spread in the market (Association2 2008). The third option is the eCall. This platform already exists in each car if the driver owns a mobile device and offers the opportunity to add more services based on UMTS. The GPS localization could also be a starting point for more valueadded services (Steiger 2008; Supplier1 2008). The importance of developing and integrating an automotive service platform into the car is beyond all questions. Probably, the toll system is the first solution on which will be worked on because the essential infrastructure with high stability and security already exists. An availability of $100 \%$ is already given on German highways and secondly the technology can be extended to cities and federal roads. This technology is already implemented in the VICS-system at the Japanese capital, Tokyo (VICS-Center 2008).

Another trend is the development of process models for the design of automotive software and services and the development of tools for the process models. The experts mentioned three topics. First of all, software engineering concepts have to be considered when developing Automotive Software and Services and developing tools have to be defined (Consultant1 2008; Consultant3 2008; OEM1 2008; OEM3 2008). The difficulty is that a mechanical engineer is not a software developer and long-established engineers will refuse to go new paths. The second trend is a change of paradigms in the automotive industry. The industry is nowadays focused on a distinctive customer orientation, instead of product orientation is it was in the past (Association2 2008; Association3 2008; Consultant3 2008; OEM2 2008; OEM3 2008; Supplier1 2008). Customers' wishes and expectations are the most important part and industry has to offer affordable services. The 
business case of selling Automotive Software and Services is not any longer to sell them as a product; the role they play as value-added services has to come to the fore. There may not raise a political discussion about the different social classes which can afford services or not. Especially, safety services have to be affordable for every customer. Only in value-added services there can be a differentiation between social classes and what they can afford (3rdParty3 2008). The third topic deals with the integration of the various stakeholders into the process. Automotive Software and Service Engineering is a very complex process which requires a lot of different people working together to be successful (Association2 2008; Association3 2008; Consultant1 2008; Consultant3 2008; Supplier1 2008). There is a need to look outside the box. Automotive technicians, business administrators, automotive engineers and software engineers have to work in one team (Consultant1 2008). Customer orientation and integration of different people are already partially realized but the integration of software engineering concepts is still in its early stages and requires much more work.

An important trend is the determination of norms and standards (3rdParty1 2008; 3rdParty2 2008; 3rdParty3 2008; 3rdParty4 2008; Association1 2008; Association2 2008; Consultant1 2008; Consultant2 2008; Consultant3 2008; Consultant4 2008; OEM2 2008; Supplier1 2008; Supplier2 2008). It is necessary to find common architectures to build Automotive Software and Services. There was already an attempt called AUTOSAR, which was more or less successful (Consultant1 2008; Supplier2 2008). There is the vision to offer developers an unified API that they can develop interactive mobile services in the car (Hoffmann et al. 2007). It is also necessary to find a mutually acceptable solution that can support future developments in a better, faster, and more efficient way.

"Improved fuel economy triggered by software." This trend is in the context of high energy and resource prices absolutely critical (3rdParty1 2008; 3rdParty3 2008; Association1 2008; Association2 2008; Consultant2 2008; OEM1 2008; OEM2 2008; Supplier2 2008). It is not only important for OEMs and suppliers, it is also a distinguishing feature for customers. Applications which improve fuel economy on the one hand and reduce $\mathrm{CO} 2$ emissions on the other are called killer applications in Automotive Software and Service Engineering for the future. The customer itself will recognize a high value. Therefore, he will spend more money on software when purchasing a new car. Issues such as autonomous driving, dynamic and environmental route guidance and driver assistance systems are more and more important and can also be categorized as killer applications. This trend will shape the future for Automotive Software and Services because alternative vehicle engines are still far away from reality (OEM1 2008; OEM2 2008). Customer advocates and automotive associations are supporters of these technologies. Even OEMs realize that energy intensive new systems are not the right thing to invest in and concentrate on energy-efficient ones.

In Figure 4, dependencies between challenges and trends are presented. A " $x$ " indicates that the current trend might be a solution for the challenge. This is not a 
classification according to the literature, but it shows the experts' opinion of what trends could help to remove obstacles in future developments. Trends are sorted according to their current completion level in practice. The challenges are arranged according to the number of possible solution dimensions.

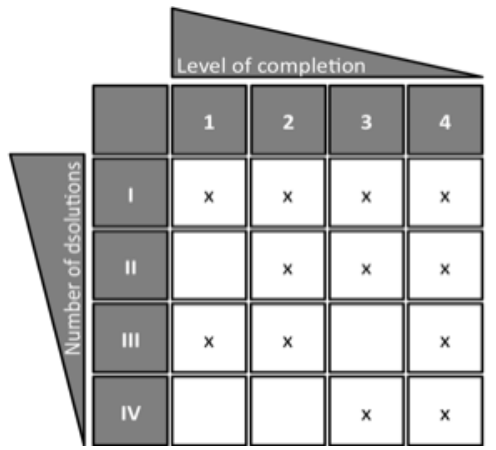

\section{Trends}

1:Killer application: save fuel

2: New process models

3: Automotive Service platform

4: Norms and standards

\section{Challenges}

I: Development costs

II: Life cycles cars vs. software/service

III: Privacy protection in connected cars

IV: Synergetic effects

Figure 4: Challenges solved through development trends

\section{Implications and Future Prospects}

In future, Software and Service Engineering will play a key role. Not only OEMs and suppliers will be highly interested in this topic, but also all the other stakeholders of the automotive industry like telecommunications companies and customers. The very high response rate of the conducted expert survey demonstrates that, too. The scope of our study was focused on Germany and the German market. In the future, we would like to extend our study to the international market; including also the view of important pioneers in the field of Automotive Services in Asia (e.g. Japan).

The interviews with the different stakeholders have confirmed the results of some other studies in this topic. Our research shows the importance of mobile value-added applications in the vehicle for the future development. However, neither manufactures nor their suppliers or external providers have currently the necessary competence to purposeful design and implement Automotive Services. A necessary core competence for this purpose is the selection of new ideas, concepts and technologies for services in the "automotive" area. The explicit aim of this study was the genuine rendition and analysis of the subjective opinions of topranking experts being distinct stakeholders of the automotive industry.

In our study, the following components for Automotive Software and Service Engineering can be derived (Fig. 5). The degree of cooperation, which is necessarily included in the development process, raises more and more in direction of norms and standards. Moreover, customer's visibility of these software or services is actually only possible when killer applications are realized. 


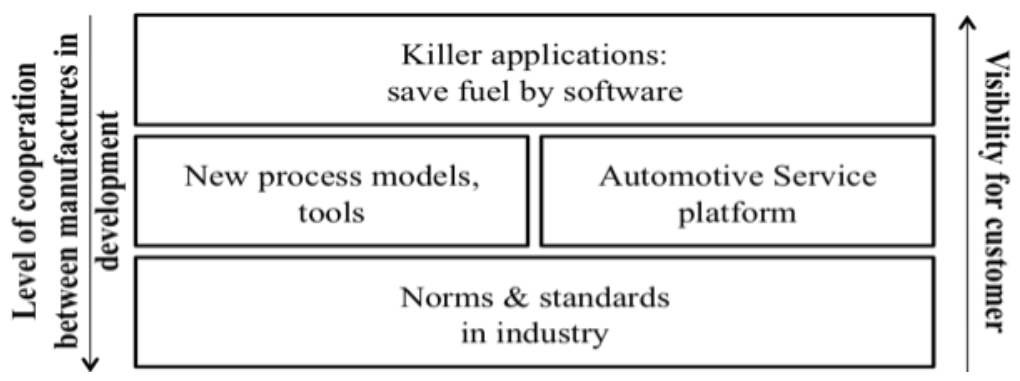

Figure 5: Components of Automotive Software and Service Engineering

Our further research is aimed at the development of a tool-supported framework for systematic prototyping of future Automotive Software and Service together with an OEM. The framework itself describes the areas of prototyping with their respective stakeholders. The tool provides engineers a way of prototyping interactive mobile applications and services to be able to pilot and evaluate this concept in the context of the vehicle. After answering these questions, there are many opportunities to develop innovative, future-directed Automotive Services on a large scale without high initial costs and without piloting with customers.

\section{List of Interviews and References}

3rdParty1 (2008) Expert interview. Employee of company 1.

3rdParty2 (2008) Expert interview. Employee of company 2.

3rdParty3 (2008) Expert interview. Employee of company 3.

3rdParty4 (2008) Expert interview. Employee of company 4.

Association1 (2008) Expert interview. Member of association 1.

Association2 (2008) Expert interview. Member of association 2.

Association3 (2008) Expert interview. Member of association 3.

Bakeman R (2000) Behavioral observation and coding. In: Reis T, Judge EM (Ed.)

Handbook of Research Methods in Social and Personality Psychology.

Cambridge University Press, New York.

Bubb H (2003) Fahrerassistenz primär ein Beitrag zum Komfort oder für die

Sicherheit? In: VDI (Ed.) Der Fahrer im 21. Jahrhundert. VDI-Verlag,

Düsseldorf: 25-33.

Consultant1 (2008) Expert interview. Employee of consultant company 1.

Consultant2 (2008) Expert interview. Employee of consultant company 2.

Consultant3 (2008) Expert interview. Employee of consultant company 3. 
Consultant4 (2008) Expert interview. Employee of consultant company 4.

Dieckmann A (1995) Empirische Sozialforschung. Grundlagen, Methoden, Anwendungen. Hamburg.

Ehmer M (2002) Mobile Dienste im Auto - Die Perspektive für Automobilhersteller? In: Reichwald R (Ed.) Mobile Kommunikation. 1 Auflage, Gabler Verlag, Wiesbaden: 459-472.

Frost\&Sullivan (2003) Customer Attitudes

Fuhr A (2001) Die Telematik ist tod - es lebe die rollende Schnittstelle. In: Proceedings of the Jahrestagung Telematik, Bonn.

Gläser J, Laudel G (2004) Experteninterviews. 1, UTB Verlag, Wiesbaden.

Greve W, Wentura D (1997) Wissenschaftliche Beobachtung: Eine Einführung. PVU/Beltz, Weinheim.

Harkness J, Mohler P, Schneid M, Bernhard C (1998) Inventives in Two German Mail Surveys 1996/79 \& 1997. Zuma-Nachrichten Spezial, 4 pp. 201-218.

Hartmann J (2004) Wo viel Licht ist, ist starker Schatten - Softwareentwicklung in der Automobilindustrie. Automatisierungstechnik, 52 (8): 353-358.

Hoffmann H, Leimeister JM, Krcmar H (2007) Anforderungen an Werkzeuge zum Prototyping von Automotive Services. In: Proceedings of the Multikonferenz Wirtschaftsinformatik, München - Garching.

Landis JR, Koch GG (1977) The measurement of observer agreement for categorical data. Biometrics, 33 159-174.

Leimeister JM, Knebel U, Krcmar H (2007) RFID as enabler for the boundless real-time organisation: empirical insights from Germany. IJNVO, 4 (1): 45-64.

Lombard M, Snyder-Dutch J, Bracken CC (2002) Content analysis in mass communication: assessment and reporting of intercoder reliability. Human Communication Research, 28 597-604.

Mercer (2004) Future Automotive Industry Structure (FAST) 2015. Henrich Druck + Medien, Frankfurt a. M.

Mohan LR (2006): Driving down the Fast Lane: Increasing Automotive Opportunities the EMS Provider Way http://www.frost.com/prod/servlet/marketinsight.pag?docid $=67150588,19.07$.

Nieschlag R, Dichtl E, Hörschgen H (2002) Marketing. 19, Duncker\&Humboldt, Berlin.

Nora S, Minc A (1978) Die Informatisierung der Gesellschaft. 1, Campus Verlag, Frankfurt am Main. 
OEM1 (2008) Expert interview. Employee of manufacturer 1.

OEM2 (2008) Expert interview. Employee of manufacturer 2.

OEM3 (2008) Expert interview. Employee of manufacturer 3.

Porst R (1999) Thematik oder Incentives? . Zuma-Nachrichten, 45 72-87.

Pretschner A, Broy M, Krüger H, Stauner T (2007) Software Engineering für Automotive Systems - A Roadmap. In: Proceedings of the International Conference on Software Engineering, Minneapolis.

Reichwald R, Krcmar H, Reindl S (Hrsg.) (2007) Mobile Dienste im Auto der Zukunft EUL Verlag, Lohmar - Köln 2007.

Reichwald R, Meier R, Fremuth N (2002) Die mobile Ökonomie - Definitionen und Spezifika. In: Reichwald R (Ed.) Mobile Kommunikation 1Auflage, Gabler Verlag, Wiesbaden.

Rubin HJ, Rubin IS (2005) Qualitative Interviewing: The Art of Hearing Data.

Saad A (2003) Prototyping bei der BMW Car IT GmbH. Java Spektrum, (2): 49-53.

Springer J (2008) Mauttechnologie: Plattform für Dienste im Fahrzeug. In:

Proceedings of the Das vernetzte Automobil, München.

Statistisches Bundesamt (2006) Verkehr in Deutschland 2006. SFG Fachverlage, Wiesbaden.

Steiger P-E (2008) 112 and eCall: The LifeService platform. In: Proceedings of the Das vernetzte Automobil, München.

Stolte P (2008) Das Auto im Connected Life. In: Proceedings of the Das vernetzte Automobil, München.

Supplier1 (2008) Expert interview. Employee of supplier 1.

Supplier2 (2008) Expert interview. Employee of supplier 2.

Supplier3 (2008) Expert interview. Employee of supplier 3.

VICS-Center (2008) Vehicle Information and Communication System (VICS), Tokio.

Werder H (2005) Verkehrstelematik als Element der Verkehrspolitik. Olten. 